\title{
CIUDAD LIBERADA \\ Aproximación antropológica a la tensión entre lo público y lo privado: Puerto Norte, Rosario
}

\author{
Marianela Casado \\ Universidad: Universidad Nacional de Rosario, Argentina \\ Tutor de la Investigación: Cristina Bloj \\ marianelacasado11@gmail.com
}

\section{RESUMEN}

El siguiente trabajo presenta una investigación antropológica acerca del proyecto urbano público- privado Puerto Norte en la ciudad de Rosario, Argentina. Dicho proyecto ha generado un fuerte contraste y segregación socio- espacial con su entorno barrial. Por un lado, se encuentra el nuevo proyecto de renovación urbana Puerto Norte característico por sus edificios de alta gama y por su espacio público construido sobre la costa del río Paraná, el cual es poco utilizado y se encuentra destinado y relacionado principalmente con usos asociados a los edificios de vivienda y comercios ubicado en el mismo proyecto. Por otro lado, se encuentra a pocos metros de Puerto Norte, un tradicional barrio obrero y un conjunto de asentamientos irregulares que conviven con estas nuevas formas urbanísticas privadas y excluyentes, funcionales a la especulación financiera e inmobiliaria.

El trabajo propone reflexionar y problematizar acerca del proceso de privatización que se desarrolla en el espacio donde se ubica el proyecto urbano.

Palabras claves: ciudad, barrio, espacio público y privatización

\begin{abstract}
The aim of this paper is to show an anthropologic research of the urban public-private Puerto Norte Schedule in Rosario city, Argentina. This schedule has caused a strong contrast and segregation in this neighbourhood. On one hand, Puerto Norte redevelopment has brought high skyscrapers with technology and a public space to be used by the dwellers or people related to these properties. On the other hand, in an area that it is not very far away from Puerto Norte there is a traditional working class neighbourhood and a group of shanty areas that coexist with these new private exclusive urban zones that are functional for the financial and estate agency speculations.

The paper proposes to reflect and problematize about the privatization process that develops in the space where the urban projet is located.
\end{abstract}

Key words: city, neighbourhood, public spaces and privatization 


\section{PRESENTACIÓN}

El barrio Puerto Norte de la ciudad de Rosario Argentina, es un proyecto urbano que se encuentra dentro de un gran proyecto denominado: "Centro de Renovación Urbana Scalabrini Ortiz". Se trata de una operación público- privada que fue llevada a cabo en dos fases, desde el año 1996 hasta la actualidad. En la $1^{\circ}$ fase se construyó el parque público y circuito recreativo Scalabrini Ortiz, ubicado en la calle Central Argentino 545, también se construyó el shopping Alto Rosario y el Supermercado Coto. En la $2^{\circ}$ fase, que comenzó en el año 2005, se lleva a cabo el Plan especial de Puerto Norte (ordenanza $\left.n^{\circ} 7892 / 05\right)$. Puerto Norte se encuentra ubicado en la avenida Luis Cándido Carballo 148. En esta segunda fase se expulsó a los pobladores ubicados en la zona durante muchos años, se destruyó parcialmente y reciclaron edificios del extremo norte del antiguo puerto de Rosario, para construir otros de alta gama y concretar un proyecto de renovación urbana. Con dicho Plan especial se encareció la vida urbana de la zona y se construyó un espacio público en la costa del río Paraná. El acceso a éste se encuentra obstruido por lujosas edificaciones las cuales están custodiadas por seguridad privada y generan un uso obstaculizado del parque público.

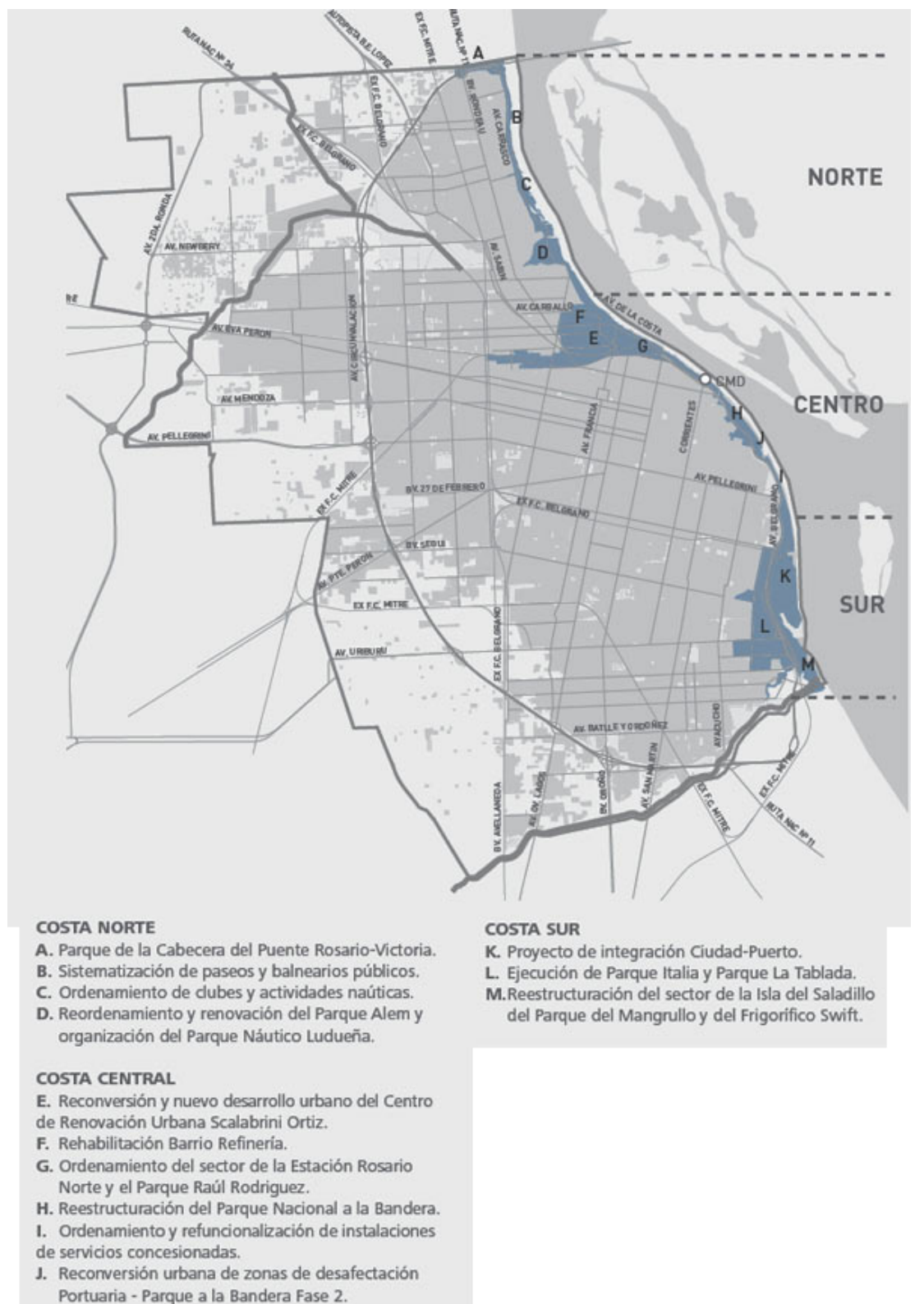

Mapa de la ciudad de Rosario sobre la costa del Río Paraná. Ubicación de Puerto Norte en COSTA CENTRAL (E) Fuente electrónica: http://www.cafedelasciudades.com.ar/planes 119.htm (Consulta: 27/04/18)

En paralelo a estas nuevas edificaciones, es decir cruzando la avenida Luis Cándido Carvallo, se encuentra el barrio Islas Malvinas, o más conocido como Barrio Refinería. Se trata de uno de los barrios más antiguos de la ciudad de Rosario, su nombre se debe a la primera fábrica de azúcar refinada del país (construida en 
el año 1887), creciendo como barrio y zona de obreros e inmigrantes, no sólo por el trabajo en la refinería sino también por la inmediatez a la zona portuaria del extremo norte de Rosario.

Puerto Norte, es un proyecto de renovación urbana que visibiliza la liberación de la planificación urbana, principalmente, en manos de empresas e intereses privados. El proyecto urbano de la ciudad se presenta como proyecto público- privado, pero responde en realidad, a un proceso de privatización del suelo. En la operación público-privada de Puerto Norte, la empresa urbanizadora construyó espacio público a cambio del uso del suelo para los proyectos privados, pero la funcionalidad de lo público no se hace presente y tiende a coartar la continuidad costera tradicional de espacios públicos sobre el río Paraná. Hoy en Rosario puede verse dicho emprendimiento construido en la costa del río Paraná, el cual no tiene otro objetivo más que la especulación financiera y la inversión inmobiliaria.

Los objetivos del presente trabajo de investigación son: conocer y reflexionar acerca de los usos y representaciones del espacio público de Puerto Norte; analizar el contraste y oposiciones que existe entre Puerto Norte y su entorno barrial, teniendo en cuenta las relaciones, prácticas y representaciones sociales de diferentes actores sociales.

Hipótesis: la construcción del proyecto Puerto Norte da cuenta del proceso de privatización que se desarrolla en el barrio, este proceso de privatización se puede observar en los cambios estéticos y arquitectónicos de los nuevos edificios construidos, hoteles de alta gama, edificios de oficinas, comercios a los que pueden concurrir personas de alto poder adquisitivo y en los espacios públicos custodiados por seguridad privada. A su vez, el espacio público del proyecto de renovación urbana, genera una disrupción con los continuos parques públicos que hay a lo largo de la costa del río Paraná, aspecto que también da cuenta del proceso de privatización que se lleva a cabo en la zona.

En el presente trabajo se propone estudiar la identidad barrial y usos de espacios de Puerto Norte y su entorno inmediato, a partir de un enfoque metodológico llamado etnográfico. El enfoque metodológico a partir del cual se ha realizado la investigación es cualitativo. El estudio etnográfico no sólo se realiza a partir de un trabajo con textos teóricos que refieren a la temática estudiada, sino también requiere de un tiempo prolongado en el campo realizando observaciones y conociendo la cotidianeidad barrial. El encuentro con sujetos, habitantes, vecinos y trabajadores vinculados al espacio donde se llevó a cabo el trabajo de campo, requirió de la realización de entrevistas en profundidad, las cuales son la técnica que permite al antropólogo acceder al universo de significaciones del actor y es también una instancia de observación, ya que al material discursivo debe agregarse el contexto del entrevistado ${ }^{1}$ (Guber, 2009)

Los sujetos entrevistados para la presente investigación fueron seleccionados, teniendo en cuenta la idea de que éstos tengan un conocimiento (historias, vivencias, ideas e imaginarios) diverso de los usos, funciones, características y particularidades del espacio de Puerto Norte y entorno barrial.

\section{LA HISTORIA DEL BARRIO DONDE ACTUALMENTE SE UBICA PUERTO NORTE}

"La historia del espacio debe rendir cuenta tanto de los espacios de representación como de las representaciones del espacio, pero sobre todo de sus vínculos mutuos y de los lazos con la práctica social [...] El punto de partida, son los ritmos espacio- temporales de la naturaleza transformados por una práctica social" (Lefebvre, 2014:170).

A partir de las palabras de Lefebvre (2014) en las que expone la importancia de pensar la historia del espacio desde el vínculo entre las representaciones del mismo y los lazos con la práctica social, es que se considera pertinente dar a conocer un breve recorrido histórico de las primeras prácticas sociales- políticas- económicas (y sus respectivas mutaciones a lo largo del tiempo) que fueron llevadas a cabo en la zona donde se encuentra ubicado hoy, el actual proyecto urbano Puerto Norte en Rosario.

Las tierras en las que se ha construido el proyecto urbano Puerto Norte, es el espacio donde históricamente se encontraba el extremo norte del antiguo puerto de Rosario, las cuales fueron un importante zona industrial

\footnotetext{
${ }^{1}$ El presente trabajo de investigación se realizó a partir de un trabajo de campo realizado a lo largo del año 2017. Las horas de trabajo en el campo fueron en total 20 horas, en las cuales se realizaron observaciones de campo y entrevistas en profundidad grabadas y posteriormente desgrabadas de manera textual.
} 
y productiva. El puerto fue construido a finales del siglo XIX en una zona que se consideraba estratégica por su cercanía a la región productiva agrícola y ganadera más importante de Argentina. Rosario tenía la particularidad de poseer $15 \mathrm{~km}$ de ribera continua junto al río Paraná y geográficamente poseía una posición privilegiada por estar ubicada en el centro del corredor bioceánico y de la hidrovía Paraguay-Paraná. Fue así que en 1852 la apertura de las vías fluviales interiores, convierte a Rosario en el centro de las actividades económicas del interior del país y posteriormente como uno de los puertos que estableció líneas de navegación con Europa.

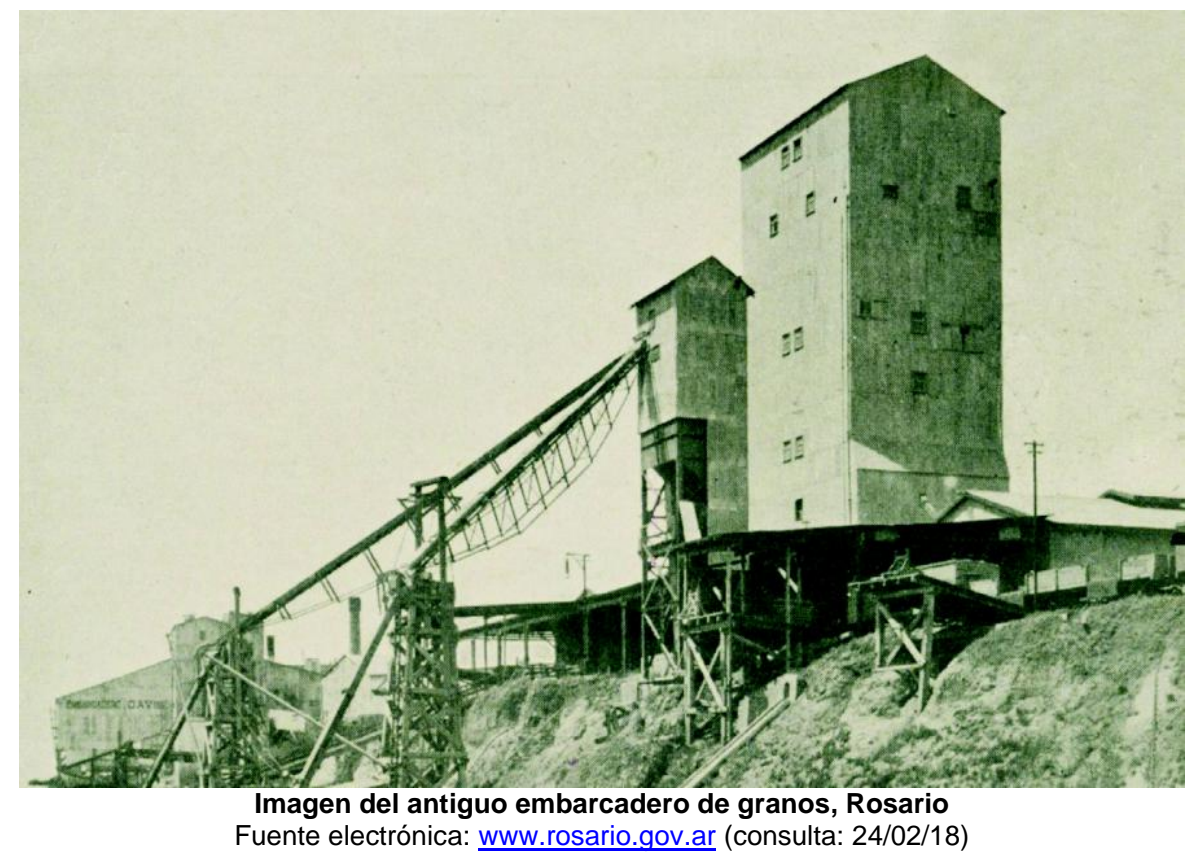

En el puerto de Rosario durante el siglo XX se realizaron obras de construcción de nuevos muelles y la terminal se posicionó como uno de los puertos más importantes de Latinoamérica, llegando a convertirse, a mediados de siglo, en la principal puerta de salida de la producción de granos del país. Años más tarde, en 1942 se nacionalizó el puerto, centrándose su administración en la Ciudad de Buenos Aires y en 1994 el puerto es transferido al Ente Administrador Puerto Rosario (EN.A.P.RO) (Sánchez Pombo, 2001)

El extremo norte del puerto rosarino se encontraba ubicado en lo que actualmente conocemos como la intersección de las calles Av. Francia y Av. Cándido Carvallo, a su vez esta zona de la ciudad además de contar con una parte del puerto era considerada la zona más importante de la ciudad en actividades productivas e industriales. Rosario a partir del 1854 comenzó a desarrollar el sistema ferroviario, trayendo como resultado una gran expansión económica. Para 1870 el tramo ferroviario Rosario- Córdoba se finaliza, luego se concreta el ferrocarril Rosario- Casilda en 1883 y para 1890, la ciudad contaba ya con cinco estaciones ferroviarias: Ferrocarril Central Argentino; Ferrocarril Oeste Santafesino; Ferrocarril Buenos Aires y Rosario (Sunchales); Compañía Fives Lilles (Francesa) y Ferrocarril Córdoba y Rosario.

Posteriormente se localizó en el sector, al norte de las hoy llamadas "tres vías" (pertenecientes a los Ferrocarriles Central Argentino, Provincial de Santa Fe y Córdoba-Rosario), la Refinería Argentina de Azúcar en 1887 (imagen de la fábrica a continuación). Allí se refinaba el azúcar que llegaba desde la provincia de Tucumán por el Ferrocarril Central Argentino, para luego ser cargada en los barcos que la exportaban. Las actividades de refinado, y las instalaciones y talleres ferroviarios se convirtieron en las principales fuentes de trabajo de la ciudad de Rosario, provocando en el sector el surgimiento del Barrio Refinería alrededor de los años 1890, una de las principales barriadas obreras de la ciudad como afirma Sánchez Pombo (2001).

Lo que hoy se conoce como el ex barrio Refinería a finales del siglo XIX y principios del siglo XX fue el barrio donde se estableció, al norte del ferrocarril, la clase obrera de manera espontánea sin una gestión urbanizadora. Tanto la zona del puerto como las conexiones ferroviarias, constituyeron una fisura en la composición de la ciudad, ya que se marginó a los barrios del norte por su ubicación. Como consecuencia las empresas ferroviarias debieron construir un paso a nivel sobre el Cruce Alberdi; $y$, en 1908, un paso bajo las vías que fue habilitado con el nombre de Celedonio Escalada. Estos caminos, constituyeron los únicos puntos de cruce del área ferroviaria por largo tiempo. 


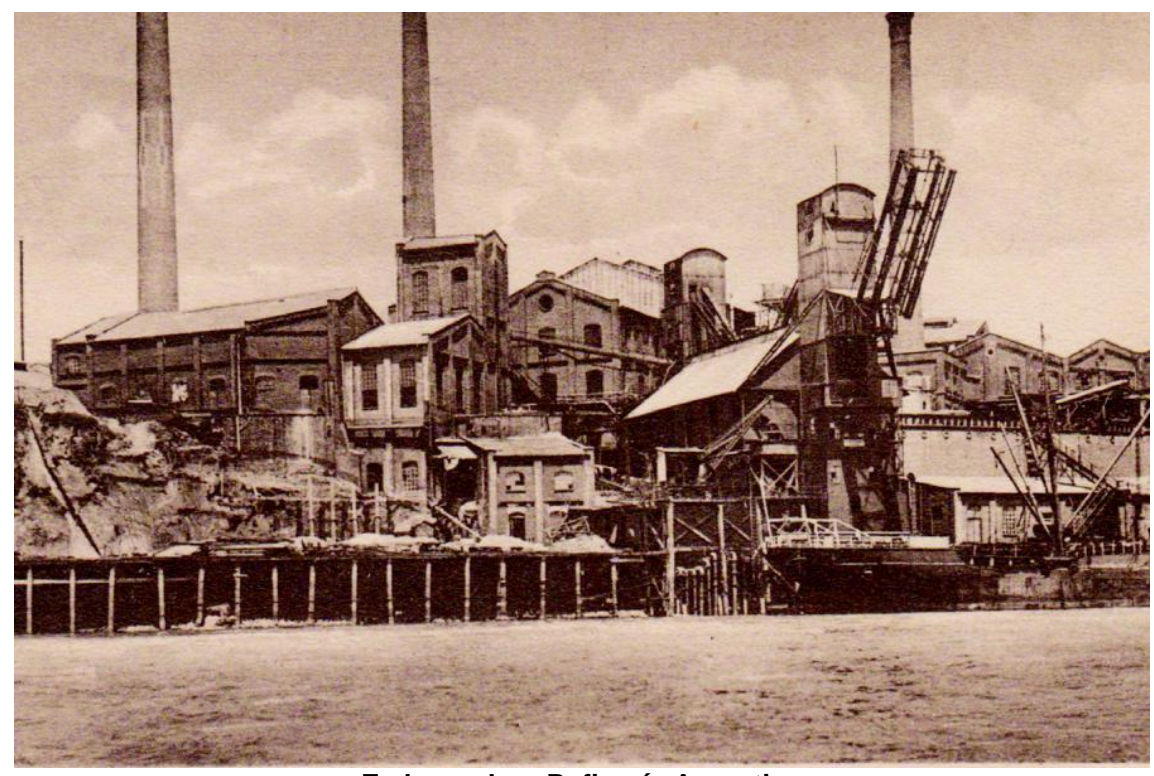

Embarcadero Refinería Argentina

Fuente electrónica: www.rosario.gov.ar (consulta: 24/02/18)

En las primeras décadas de 1900 la industrialización continuó en el sector con un perfil obrero y una fuerte radicación industrial-residencial que se fue afianzando con la instalación de otros establecimientos: la Cervecería Quilmes y la Arrocera Argentina sobre Av. Alberdi; más al noroeste la Aceitera Santa Clara, la Algodonera Argentina sobre calle Vélez Sarsfield y más tarde la Maltería SAFAC y las Bodegas Giol. Todas estas industrias serán las que generen y orienten el desarrollo industrial posterior.

En 1930 la Refinería dejó de funcionar. Luego, se destinó a la elaboración de tanino, quedando desocupadas las instalaciones hasta que en 1947 la adquirió la empresa SAFAC, inversión de capitales alemanes, instalando la Maltería Argentina, para la elaboración de malta y cebada para producir cerveza. En el año 1953, comenzó a funcionar la Maltería Argentina, debido a su nacionalización pasó a ser propiedad de la Junta Nacional de Granos. El nuevo uso industrial de la antigua Refinería se insertó en las estructuras edilicias de las edificaciones existentes pero adecuando la tipología a los nuevos requerimientos del proceso productivo, más tarde la edificación se complementó con la construcción de silos (Sánchez Pombo, 2001).

En el año 1963 la Municipalidad de Rosario crea un Plan Regulador con el fin de darle un nuevo destino al sector norte de la ciudad: habilitar desde el centro de la ciudad la accesibilidad a la zona norte que había quedado marginada por las extensiones férreas e industriales y así integrarla al resto del tejido de la ciudad.

Posteriormente atendiendo a dichos objetivos del Plan Regulador se busca con el Plan Director de 1991 comenzar a decidir qué hacer en la zona norte de la ciudad, desmantelada e inutilizada. Es así que esta zona toma su rumbo a partir del Plan especial Puerto Norte, un plan público- privado orientado a la renovación de la zona portuaria e industrial, basado principalmente en la inversión inmobiliaria y la construcción de viviendas para la clase social alta.

\section{PUERTO NORTE: UN PROYECTO URBANÍSTICO PÚBLICO-PRIVADO}

Puerto Norte se ubica dentro del gran proyecto urbano denominado Centro de Renovación Urbana Scalabrini Ortiz, operación público privada que comenzó a realizarse en la ciudad de Rosario en el año 1996. Este gran proyecto se divide en dos fases y Puerto Norte corresponde a la segunda fase que es considerada un Plan Especial dentro del Sistema de Planeamiento Municipal de Rosario ubicado dentro del Plan Urbano Rosario 2007-2017.

El ámbito de aplicación del proyecto Puerto Norte comprende una zonificación general que está compuesta por suelos destinados a usos privados y suelos públicos destinados a parques, equipamientos públicos y trazados básicos y complementarios. La urbanización comprende tierras del Estado Nacional y predios privados sujetos a reconversión correspondiente a empresas cerealeras. 


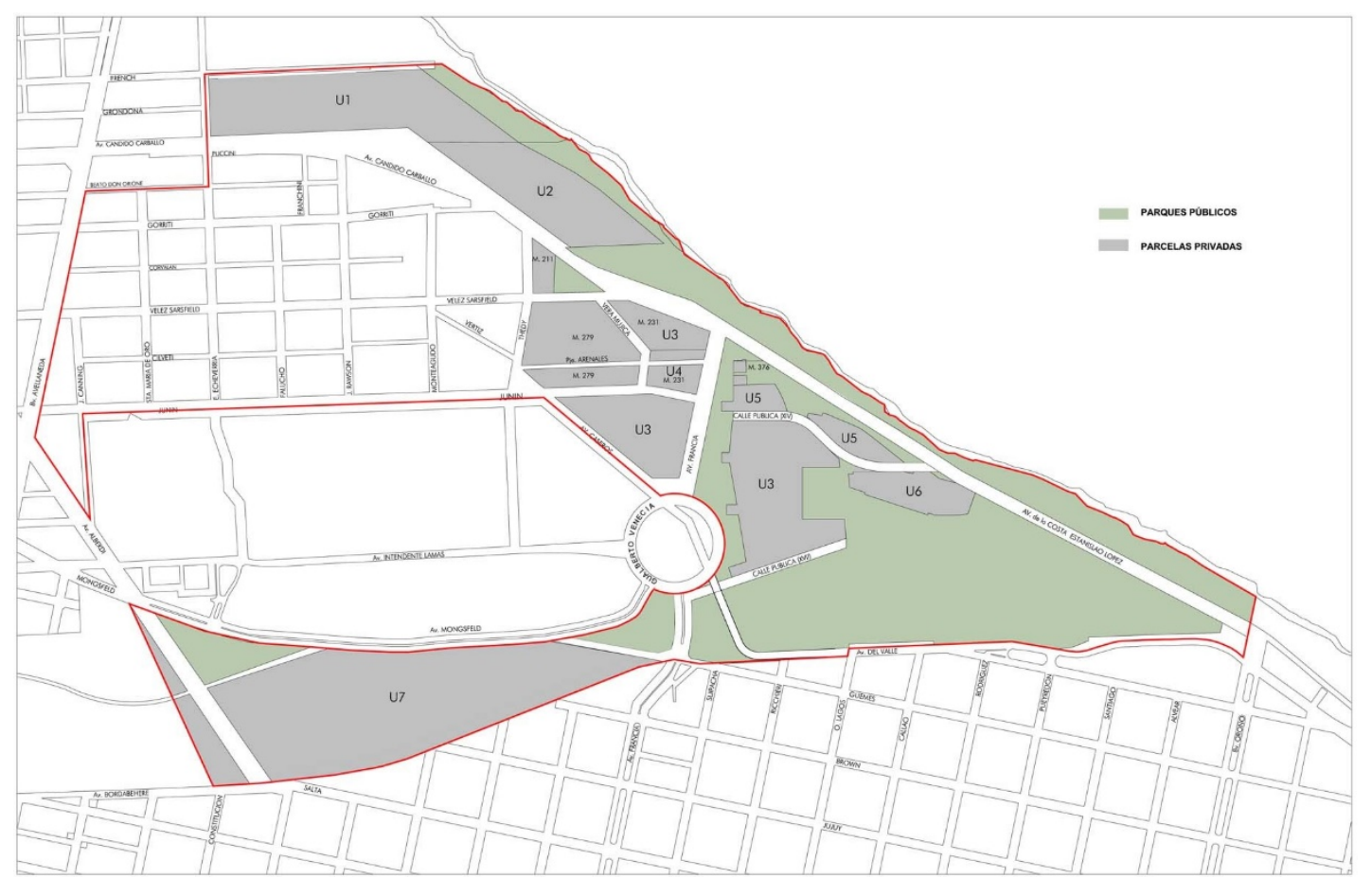

Gráfico donde se detallan espacios públicos y privados de la 2da Fase de desarrollo del "Centro de Renovación Urbana Raúl Scalabrini Ortiz"

Fuente electrónica: https://www.rosario.gov.ar/normativa/verArchivo?tipo=pdf\&id=37481 (consulta: 28/04/18)

La zona analizada en el presente trabajo comprende un polígono definido como Unidad de Gestión 1 y 2 en el artículo 6.1 y 6.2 de la ordenanza 7.892/05 (Ver en gráfico anterior ubicación de las Unidades de gestión 1 y 2, U1 y U2). Respecto a lo que refiere al espacio público de las Unidades de Gestión 1 y 2, lo público está conformado por un paseo ribereño y por espacios y parques que poseen piso seco. Los espacios públicos construidos en el proyecto urbanístico Puerto Norte dan cuenta de un tratamiento y planificación que responde a usos obstaculizados del mismo. En primer lugar el acceso al espacio público de Puerto Norte se encuentra obstruido por edificios de alta gama ubicados en el ingreso (sobre la Av. Cándido Carvallo): hay una serie de edificaciones y torres para vivienda de hasta 23 pisos, un lujoso hotel de 4 estrellas que cuenta con 6 pisos y tres subsuelos (el cual fue construido sobre la estructura de los antiguos Silos) y el ingreso al estacionamiento de vehículos privados.

En ambas unidades de Gestión (1 y 2) el tratamiento de los espacios de uso público de Puerto Norte quedó a merced del urbanizador, esto implica que los costos quedaron a cargo de las empresas privadas pero también parte de las decisiones que refieren a infraestructura, tipos y calidad de materiales, entre otros. Ahora bien, ¿qué posición tiene la Secretaria de Planeamiento Municipal en este tipo de proyectos basados en convenios público- privado? En ambas ordenanzas puede observarse que la aceptación de la donación de suelos para espacios públicos (con su infraestructura correspondiente) como así también, la coordinación y acuerdos en relación a las afectaciones y división del suelo, depende de la Secretaria de Planeamiento. Es decir que las decisiones que se tomaron en la construcción del espacio público tiene una doble responsabilidad: de la Secretaria de Planeamiento Municipal y de las empresas urbanizadoras.

A partir de la obra de Gorelik (2008), se propone analizar los usos y sentidos del espacio público en el caso de Puerto Norte. El autor analiza en El romance del espacio público la categoría espacio público y sus significaciones a partir de los años 1980 y 1990 en Argentina. El autor considera que esta categoría es decisiva en el cambio de representaciones sobre la ciudad, la ciudad de los negocios ya no goza de buena prensa, no siendo así la ciudad de los espacios públicos: "El éxito de esta categoría puede notarse en el hecho de que, desde los años ochenta hasta hoy, sigue siendo la preferida, no sólo en el mundo cultural y académico, sino también entre los gobiernos municipales y lo que es más significativo, los grupos empresariales para pensar la transformación de la ciudad en un sentido progresista" (Gorelik, 2008:2)

El espacio público ubicado en Puerto Norte es un espacio construido a partir de un convenio público-privado. Su particularidad refiere a que se encuentra detrás de una serie de edificios comerciales y para vivienda, además no cuenta con espacios verdes, es decir solo posee piso seco y está custodiado por seguridad 
privada. Se trata de un espacio muy particular ya que muchos días está vacío y los usos que suele tener son especialmente los días de fin de semana y se relacionan con la concurrencia a los comercios que allí hay (bares, cervecerías, heladerías, etc.)

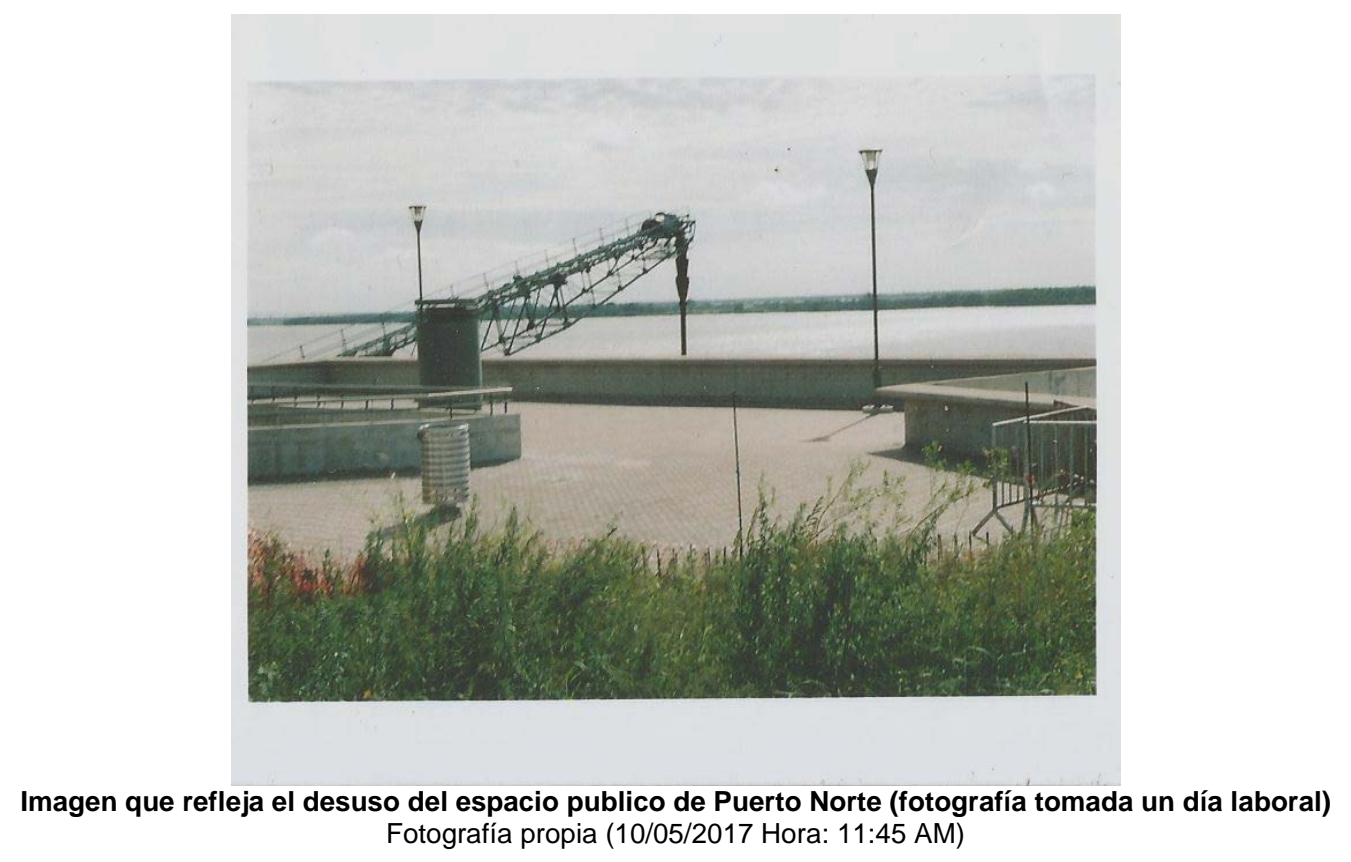

¿Cómo puede pensarse la categoría espacio público en este sitio de la ciudad de Rosario? Gorelik (2008) propone pensar que el espacio público urbano se ha convertido en un espacio espectral, y la categoría de espacio público, en un fetiche que enmascara esa situación.

En el material registrado realizado a partir de la técnica de investigación observación de campo, puede verse que el espacio público de Puerto Norte es utilizado mayormente para consumir en los locales comerciales, es decir que tiene un fin turístico y comercial o funciona sólo los fines de semana (las imágenes que se exponen en el presente apartado fueron tomadas un día laboral y en ellas no se observan personas utilizando ningún espacio). Además el acceso al espacio público no está claramente delimitado, es un lugar de piso seco y está custodiado por seguridad privada:

"Me senté frente al río Paraná en uno de los bancos que hay en el espacio público. El espacio es de cemento, no cuenta con zonas que tengan césped, sólo existen canteros con plantas. El espacio público está mayormente vacío, es día de semana [...] Recorrí el espacio público caminando y observando su uso. No hay gente, sólo pasaron dos deportistas corriendo y una persona caminando que salió con una bolsa de uno de los comercios. Respecto al ingreso al espacio público este se encuentra obturado por las edificaciones. La zona del hotel, que se ve desde la avenida C. Carballo está cercada por una serie de finos cilindros metálicos" (Registro de campo, observación propia en espacio público de Puerto Norte, 10/05/17, hora: 11:30 a 12:30am)

Los entrevistados en el trabajo de campo han dado su punto de vista y representaciones acerca del espacio público de Puerto Norte. Esto ha permitido conocer los usos del espacio y a partir de él repensar y reflexionar acerca de qué sentidos tiene el espacio público del proyecto urbano. Lo que se ha concluido es que, en sí el espacio está destinado principalmente para acceder a los comercios que existen en el lugar, no tiene las características y usos de otros espacios públicos donde se observan niños jugando, deportistas, familias tomando mate, etc. ¿Qué ocurre con el uso de los espacios públicos planificados por empresas privadas preocupadas por la inversión inmobiliaria? ¿Cómo es la convivencia de la seguridad privada con las pocas personas que asisten al espacio público?

Por un lado, una mujer que vive en los asentamientos irregulares comenta en la entrevista que no usan el espacio público, sólo han ido a Puerto Norte para comprar algo en la farmacia o en el quiosco, si bien viven a pocos metros de distancia. Por otro lado, según un grupo de jóvenes que utilizan el espacio público de Puerto Norte para andar en bicicleta, es difícil el uso porque están custodiados por la seguridad, quienes en muchos casos los echan del lugar: 
Entrevistada (E): "No hay gente en el espacio público. Capaz los fines de semana se junta un poquito más de gente, nosotros mucho no vamos para allá, pero a veces sí porque hay una farmacia, hay un quiosco..." (Entrevista a una mujer que vive en los asentamientos irregulares frente a Puerto Norte, 31/09/17)

E: "Siempre a la policía o a la gente le molesta que nosotros andemos en la bici porque capaz que podemos chocar a alguien pero hasta ahora de los años que ando en bici nunca choqué a nadie ni nada por el estilo, pero siempre hay personas que cuidan a otras personas y bueno puede pasar un problema [...] y la seguridad privada, si la gente no haría problema, no llamaría a los de seguridad y no sé si tuviéramos problemas, pero como nosotros andamos a la gente le molesta y llama al de seguridad y nos hacen irnos del lugar porque supuestamente molestamos" (Entrevista jóvenes que realizan deporte en bicicletas en el espacio público de Puerto Norte, 10/06/ 17)

En este espacio la seguridad privada controla los usos que la sociedad hace del lugar lo que genera contradicciones al pensar dicho espacio como público. ¿Cuál es límite entre un espacio público y un espacio privado? ¿Qué papel tiene el gobierno municipal en la ejecución de estos espacios que terminan teniendo un carácter privado pero se los presenta como espacios públicos?

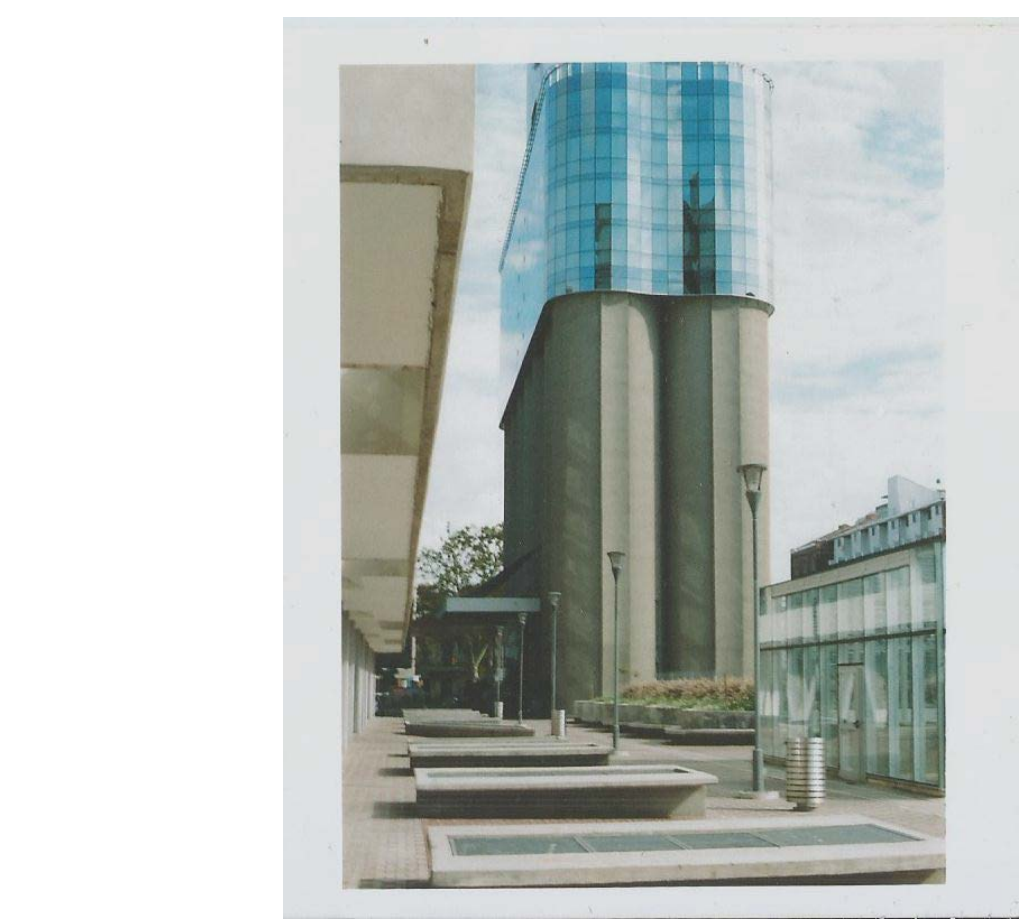

Espacio público de Puerto Norte contiguo al hotel que fue construido sobre los antiguos silos Fotografía propia (10/05/2017 Hora: 11:45 AM)

Uno de los actores sociales entrevistado que vivió en un edificio de Puerto Norte expresó que no consideraba que en el lugar haya espacios públicos, sino más bien que había pasadizos o caminos que se dirigían a los comercios o a los edificios para vivienda pero que en realidad estos pequeños caminos y espacios con vista al río no conformaban lo que comúnmente se entiende por espacio público:

"E: Dejame ver qué parte hay para el público. No hay. O sea es un pasadizo que podés ver el río por arriba, pasas por la espalda de lo que es Fórum si lo ves desde la calle, y tenés unos metros para caminar y bordear la costa. Es un paseo, que podría tener binoculares o algo, pero es para caminar un poquito y tomar unos mates y conocer los bares esos, no se puede ingresar por ningún lado además. Creo que una vez lo abrieron para que la gente pudiera conocer las dimensiones y pudiera pasear, eso lo hicieron, invitaron para que conozcan Fórum. Después tiene los jardines centrales pero nadie se sienta a tomar mate ni nada generalmente ¿no? Es un jardín que tiene una arquitectura particular, bancos largos de hormigón" (Entrevista a un sujeto que vivió y trabajó en uno de los edificios de Puerto Norte durante los años 2014-2015, 16/06/17, hora 11:00 am.)

En este sentido, el funcionario de la municipalidad de Rosario que trabaja en Planificación Urbana en la entrevista también expresó que el espacio público no funciona como debería funcionar, además considera que se trata de una parte de la ciudad que genera una disrupción, ya que el contraste con el entorno barrial y 
la inutilidad del espacio público del proyecto Puerto Norte, no permite pensarlo como un espacio socialmente justo:

"Marianela (M): Respecto al espacio público de Puerto Norte, ¿la construcción del mismo también fue parte del convenio público- privado?

E: Sí, el espacio público prácticamente en Refinería lo construye el privado y lo dona al municipio. Yo no conozco, no estoy muy interiorizado qué es lo que está pasando, pero sé que hay algunas demoras porque los empresarios no cumplen con terminar los espacios públicos que estaban convenidos [...] En Puerto Norte a lo mejor se podría haber consolidado mejor este tema del zócalo comercial porque algunas de las calles del interior estaban pensadas con este tema pero tienen esa dificultad, no hay la densidad suficiente como para mantenerse y tampoco funcionan con la ciudad porque son visitados los fines de semana básicamente, durante la semana no va nadie. Entonces es una parte de la ciudad un poco, no sé cómo llamarlo, que tiene una disrupción digamos" (Entrevista a Funcionario de la Municipalidad de Rosario en Planificación Urbana, 26/07/17, hora: $12: 00 \mathrm{am}$ )

¿Para quiénes fue pensado Puerto Norte ¿El resultado de un espacio público privatizado da cuenta de un desligamiento del Estado en cuestiones urbanas? ¿Qué importancia tiene para las empresas privadas que el municipio haya dejado en sus manos la configuración de Puerto Norte?? La planificación y ejecución de espacios públicos en manos de empresas privadas trae como resultado un espacio complejo donde convive la seguridad privada y un uso coartado, más bien destinado a ser un pasaje para dirigirse a los comercios y viviendas allí ubicadas. Las características que se han observado en el recorrido por este espacio y en palabras de diferentes actores, dan cuenta de un proceso de privatización del espacio público (el cual genera un fuerte contraste con la serie de parques públicos que hay a lo largo de la costa del río Paraná). En palabras de Gorelik (2008) un espacio público es aquel que da lugar al conflicto, a los usos diferenciados, a la reunión de personas, etc. Puede decirse que este nuevo tipo de espacio público esté más cerca de lo que el autor considera como un espacio espectral, y la categoría espacio público, que dice existir en Puerto Norte, sólo es un fetiche que enmascara la situación.

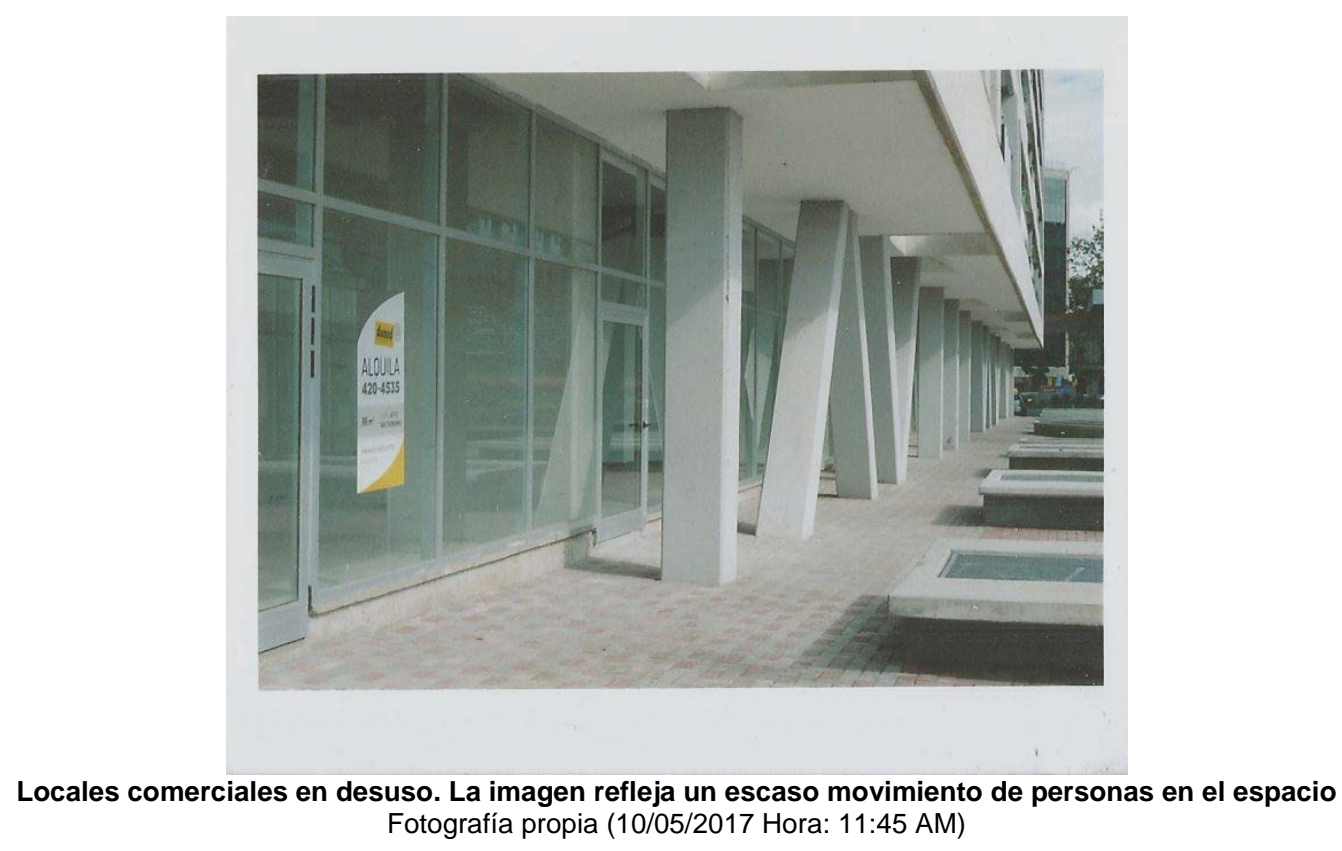

\section{RELACIONES BARRIALES Y REPRESENTACIONES SOCIALES}

En los registros realizados a lo largo del trabajo etnográfico, aparece la idea de que Puerto Norte no se encuentra integrado a la ciudad (es una disrupción), es entendido como un conjunto de viviendas de alta gama que cortan el cordón costero de la ciudad, característico por sus espacios públicos, y que poco tienen que ver con el barrio que históricamente existió y sigue existiendo allí. Por otro lado también, uno de los sujetos entrevistados expresó que las relaciones al interior del complejo de viviendas de Puerto Norte son escasas y más aun con las personas que viven antiguamente en las calles aledañas del barrio Refinería. 
Siguiendo a De Certau (2000) hay espacio en un lugar cuando hay cruzamiento de movilidades, el espacio se produce por las operaciones que lo orientan, lo temporalizan y lo llevan a funcionar como una unidad polivalente de programas conflictuales o de proximidades contractuales: el espacio es un lugar practicado. Siguiendo la categorización de espacio de De Certau puede preguntarse qué tipo de prácticas ocurren en los espacios de Puerto Norte, quiénes las llevan a cabo, qué movilidades existen en Puerto Norte, cómo se construye la espacialidad de ese lugar y a qué tipo de relaciones sociales y barriales habilita.

El sujeto entrevistado, que vivió en uno de los nuevos edificios de Puerto Norte, expresa su idea acerca de cómo son las relaciones al interior del barrio y caracteriza a Puerto Norte como un lugar que te vuelve ermitaño:

E: "No tenés mucha conexión con los demás, a no ser que sea un vecino bien pegado no te conectas. Hay poca gente que se abre o te invita a pasar, ha pasado que se olvidan la llave y cruzas por un balcón y ahí haces una relación, cuando pasa algo sino no es muy conectivo todo, es raro, es muy raro. Y bueno hay gente que ni siquiera la ves, llega en auto con vidrios polarizados, se baja y se van directo al ascensor. [...] En sí el lugar te hace medio ermitaño, no estás súper sociabilizado. (Silencio) Hubo muchos problemas de comportamiento, hay normas, te dicen que no comas en la pileta y había yerba, galletitas, cosas conflictivas, porque siempre la gente se empieza a quejar uno con otro, es como una gran familia y ahí empiezan los chisporroteos. Pero siempre vos ves que hay núcleos que se juntan siempre los mismos y no hay una conexión muy suelta con los demás. Este rincón es para mí, aquel para allí" (Entrevista a un sujeto que vivió en Puerto Norte, 16/06/2017, hs 11:00 am.)

El entrevistado reconoció no haber podido entablar relaciones con los vecinos del complejo, ni haber podido tener una buena experiencia en relación a los modos y tratos que los vecinos tenían para relacionarse o acordar diferentes temas que afectaban a la vecindad, como el compartir y respetar normas de los espacios de uso común. En los edificios los vecinos no se cruzan, algunos sólo llegan en auto y de allí suben directamente a su casa desde el estacionamiento, otros de los habitantes no se conocen y no hay conexión. Siguiendo la idea de De Certau (2000), las prácticas y movilidades que definen el espacio no tienden a dar cuenta de relaciones entre vecinos, más bien los espacios comunes de Puerto Norte se caracterizan por no generar relaciones de intercambio y conexión entre vecinos. Dicho en otros términos, existe un fuerte individualismo en los habitantes del sitio llamado Puerto Norte, un barrio que además se incrusta en la ciudad de Rosario ya que que no ha podido integrarse al antiguo barrio ex-Refinería:

“M: ¿Para vos cómo se integra el proyecto de urbanización de Puerto Norte al barrio en general, es decir a Refinería?

E: Quiero pensar eso para ver si realmente tiene alguna conexión. Creo que le dio valor al inmueble, únicamente y los linderos y esas avenidas ¿no? Pero no es como una unidad, no es algo que se integre. Lo han impuesto, lo clavaron. Te pueden decir que mejoraron la zona, que sí el edificio o sea se aprovechó la estructura perfecto. Pero no es como los parques que están en la costa, no te podes acercar al agua, no tenés un ingreso, no lo disfrutas. O sea es un balcón al río privado. Lo único que se me ocurre pensar ahora es cómo elevó el valor de los terrenos, se siguen levantando torres y se encontró un punto en la ciudad donde dijeron desarrollen para arriba y vendan la vista al río. No le veo conexión social" (Entrevista a un sujeto que vivió en Puerto Norte, 16/06/17, hora 11:00 am)

Gravano (2008) en su obra Imaginarios barriales y gestión social, define la categoría barrio de la siguiente forma: "lo barrial como cultura es la producción de sentido que se referencia en el espacio, la identidad, la ideología y las prácticas barriales y que adquiere significación histórica dentro de la dialéctica entre la ruptura con lo dado o naturalizado respecto de la realidad de sus actores. Cultura como metáfora social capaz de modelizar comportamientos y representaciones, que analizamos en sus mecanismos semióticos internos en relación con sus razones históricas y como instrumento de construcción de identidades. Metáfora del no control de las condiciones de existencia de sus actores, en el proceso de apropiación del excedente urbano. [...]Así, lo barrial como cultura no se reduce a vivir en un barrio sino a apropiarse y producir los significados que este horizonte simbólico contiene, como competencias para expresarse, mediante representaciones y prácticas, en distintos contextos espacio-sociales. No tiene un valor unívoco ni adherido a lo empírico en forma directa y determinante, sino simbólico, tan transformador como reproductor, tan historizador como deshistorizador. Tiene el sentido de lo incompleto y en renovación permanente. Su sentido de lo renovador se asume como lo crítico, impugnador y contrario a la estabilidad y el orden formales, institucionales y hegemónicos. (Gravano 2008:4,6)

El autor entiende lo barrial como cultura, es decir que lo barrial no se reduce a vivir en un barrio, sino a apropiarse de él, a producir y darle un sentido, que se referencie en lo espacial pero también en la identidad 
y en las prácticas barriales. Si pensamos esta idea de barrio en relación a Puerto Norte, pareciera asociarse con un lugar hecho sólo para vivir, donde las relaciones sociales y el barrio entendido como cultura, no es lo que lo caracteriza. Sin embargo, uno de los entrevistados que vive en un asentamiento irregular del ex barrio Refinería desde el año 1940 (frente a Puerto Norte) comenta que el barrio para él es el lugar donde todos se conocen, donde si necesitas algo podés pedirle a un vecino, donde entre todos se respetan y son amigos. La realidad del barrio es difícil ya que según el entrevistado los que deciden son los que tienen plata y a ellos no les queda más que aguantar y cuidar su lugar. Las palabras de este entrevistado dan cuenta del barrio como cultura, su representación acerca de las relaciones barriales expresa la idea de comunidad y ayuda mutua:

"E: Ellos no tienen nada, ellos vinieron y se colocaron ahí \{se refiere a personas asentadas de manera irregular en el terreno\}. Nosotros tenemos que aguantar sí o sí lo que diga el gobierno [...] Yo conozco a todos y me conocen todos ellos a mí. Al contrario, hay veces que estoy hablando con chicas, con esto, con aquello, como hablo con vos, pero nunca... Nunca le falto el respeto a nadie, ahí atrás \{señala su casa\} hay criaturas y yo los respeto, como a todas las chicas y los chicos. Nunca le falté el respeto a nadie, ni a ella, ni a él [...] Nos llevamos bien, no somos malas personas, somos buenos. No hay que molestar a nadie, al contrario, no tenés algo y te ayudan...Todos nos conocemos y ayudamos" (Entrevista a un sujeto que vive en los asentamientos irregulares frente a Puerto Norte, 2/9/17, hora 16:00 pm.)

De un lado de la Av. Cándido Carballo nos encontramos con el testimonio de un vecino del asentamiento irregular que expresa la unidad y colaboración que hay entre la gente que allí vive. Este barrio también tiene la particularidad de usar al máximo los espacios públicos de su entorno inmediato (calles, veredas, descampados), las entrevistas hechas para este trabajo fueron concretadas y realizadas en la calle. Pero del otro lado de la avenida, es decir en Puerto Norte, nos encontramos con un espacio público inutilizado y custodiado por seguridad privada, también con representaciones de uno de los habitantes, que expresan que no hay relaciones entre los vecinos, que ni si quiera se comunican ni se ven, que hay malos tratos, etc. La idea barrio como cultura aquí no encuentra puntos en común como así tampoco las prácticas que los definen.

\section{OPOSICIONES ESPACIALES}

"Frente al despliegue de las variadas y conflictivas espacialidades del neoliberalismo urbano, podemos encontrarnos en Puerto Norte, con una espacialidad compleja debido a la convivencia entre las clases sociales altas y bajas, en una misma zona" (Rodríguez; 2015:206).

El tradicional barrio Refinería y los asentamientos irregulares que se han construido en su cercanía, dan cuenta de un barrio habitado por trabajadores y antiguos obreros de las industrias correspondientes a la zona (refinería, puerto, maltería, etc.), como así también por sujetos que no tienen trabajos regulares. Una de las habitantes del antiguo barrio expresa recuerdos de su infancia que refieren a la identidad del barrio obrero:

"E: Yo llegué acá el 12 de marzo de 1945, cuando nací, hace 72 años. No en esta casa pero en la otra cuadra, acá Arenales al 40. Mi papá trabajaba en la casa Wilson, era donde estuvo la arenera, la arenera estaba en esta parte que da frente a Puerto Norte, ahí. [...] todos trabajaban acá, habia mucha gente que trabajaba en la maltería, y se hacían esas casitas precarias, porque era gente muy humilde, siempre hubo gente muy humilde en este barrio, era gente de trabajo" (Entrevista a señora que vive en el barrio Refinería hace 72 años, 27/11/2017, hora: 19:30 pm)

En la localización urbana Rosarina analizada en el presente trabajo de investigación, se puede observar que a pocos metros de distancia existen dos barrialidades que se oponen en muchos aspectos: físicos, arquitectónicos, estéticos y también aspectos que refieren a prácticas barriales, actividades, sentidos y representaciones acerca de los modos de pensar el barrio.

Siguiendo la obra de Signorelli (1999) en su obra Antropología urbana, la ciudad por más pequeña que sea, jamás ha sido un sistema equilibrado de relaciones humanas integradas y serenas. La autora expone en su obra la descripción de toda ciudad y considera que el principal concepto definitorio de la misma es el de conflicto.

El nuevo complejo rosarino Puerto Norte y su paralelo barrio tradicional Refinería, permiten describir una espacialidad que da cuenta del conflicto que la autora expresa respecto a las ciudades: "Las ciudades han sido siempre el punto de máxima tensión de todo sistema social, a causa de la marcada división del trabajo que las caracteriza, de la interdependencia de las funciones y del antagonismo de los intereses que de ellas derivan [...] entre relaciones sociales en el espacio y relaciones sociales con el espacio, existe una 
interdependencia que es determinante [...] hay un momento a partir del cual la fusión de situaciones sociales y espaciales produce algunos efectos pertinentes en las relaciones de clase y por esta vía, en el conjunto de la dinámica social (Signorelli, 1999: 37,41)

Los elementos espaciales y sociales de una ciudad, se fusionan y nos permiten reconocer diversos aspectos que no tienen que ver sólo con la simple ocupación física de un grupo social en el espacio. La autora propone tener en cuenta otros criterios que permiten analizar las tensiones en una ciudad: "En primer lugar un criterio económico que consiste en la verificación de las interdependencias entre la colocación espacial de un grupo y su participación en los procesos de producción; en segundo lugar un criterio sociológico que refiere a verificar la espacialidad y la dinámica social de un grupo; y en tercer lugar un criterio antropológico que consiste en verificar las interdependencias entre la colocación espacial de un grupo y construcción de su identidad en términos culturales, es decir, como percepción que el grupo tiene de sí mismo dentro de una visión general del mundo y de la vida mediata por un sistema de conocimientos y valores" (Signorelli, 1999:42)

Estos criterios permiten analizar el caso de los espacios: Puerto Norte y barrio Refinería. Respecto a cada criterio ambos espacios aparecen oponiéndose. Si tomamos el criterio económico podemos encontrarnos con dos mundos paralelos, en Puerto Norte se encuentran una serie de edificaciones, como el hotel, comercios y oficinas, que responden a actividades económicas para abastecer y satisfacer necesidades de un sector de la sociedad de clase media-alta. Refinería, sin embargo, se define por ser el clásico barrio de obreros, a su vez los habitantes de la villa tienen trabajos irregulares y esporádicos. Estas dos espacialidades responden a criterios económicos opuestos.

Respecto a los criterios sociológicos y antropológicos también nos encontramos con una importante oposición en ambos espacios. Las dinámicas sociales, los lugares de encuentro, los usos del espacio por los habitantes del barrio, la construcción de identidad en términos culturales, los conocimientos y valores en Puerto Norte y Refinería distan enormemente, en la mayoría de sus aspectos.

Esta zona rosarina, la de Puerto Norte y el ex barrio Refinería, viene a representar una espacialidad que se caracteriza por su oposición. Para comprender estas oposiciones no solo es importante observar sus aspectos externos, sino también tener en cuenta la imaginalidad de lo espacial o los sentidos que se tienen acerca del barrio, que según el autor es la mejor forma para describir y comprender un barrio:

"La imaginalidad es el resultado de concebir el barrio como un espacio con actores [...] la cuestión de los actores provoca desde ya una ruptura con las asunciones fisicistas del espacio urbano, tal como lo denunciaran numerosos autores, desde Harvey en adelante. El eje es la recuperación de la dimensión significativa, representativa, subjetiva, vivida, simbólica o cultural del espacio; en suma: el barrio con gente que vive el barrio y no sólo el barrio con gente que vive en el barrio. [...] La imaginalidad de lo espacial, tomada desde la perspectiva antropológica, implica ponderar la imagen construida en y por los actores y, de esta manera, romper con el preconcepto de la mismidad entre las representaciones de los que usan y de los que piensan la ciudad y los barrios desde el deber ser" (Gravano A. 2005: 173)

\section{CONSIDERACIONES FINALES}

A partir de las observaciones y representaciones sociales de diferentes entrevistados, es posible afirmar que el proyecto público- privado Puerto Norte se asocia más con un proyecto de carácter privado que con un proyecto de carácter público- privado. El espacio público no es utilizado como tal, los entrevistados no lo asocian con los usos de todo parque público y tampoco encuentran que pueda integrarse con el entorno barrial. El proyecto de renovación urbana ha generado un fuerte contraste con el antiguo barrio y representa un fuerte carácter de espacio privatizado, elitista y comercial.

El proyecto Puerto Norte es reciente y hay zonas que siguen en proceso de construcción, por ello es importante investigar y dar cuenta de cómo irá afectando el entorno barrial. Cabe destacar que el proyecto Puerto Norte se encuentra en una zona con gran proyección a futuro para las empresas constructores e inversores inmobiliarios. Esta zona está al lado del río y es un espacio con una vista privilegiada. En la actualidad hay proyectos y edificios en pleno proceso de construcción, terrenos en venta, empresarios que ofrecen dinero a los pobladores del antiguo barrio para que se vayan de sus casas y así poder dar rienda suelta a las nuevas edificaciones de alta gama. El presente trabajo de investigación será profundizado y continuará desarrollándose para poder registrar los cambios que vaya sufriendo la zona. 


\section{BIBLIOGRAFÍA}

DE CERTEAU M. (2000) La invención de lo cotidiano I. México: ITESO

GARCÍA CANCLINI (1996) Público- privado: la ciudad desdibujada. En Alteridades (Bs.As.) Vol. 6 №11 (510)

GERCHUNOFF P. Y CÁNOVAS G. (1994) Las privatizaciones en la Argentina. Impactos micro y macroeconómicos. En Serie de Reformas de Políticas públicas 21. (483-512) Santiago de Chile: Naciones Unidas, CEPAL.

GORELIK A. (2008) El romance del espacio público. En Revista Alteridades (México) vol.18 n³6 (33-45)

GRAVANO A. (2005) El barrio en la teoría social. Buenos Aires: ed. Espacio.

GRAVANO A. (2011) Imaginarios barriales y gestión social: trayectorias y proyecciones a dos orillas. En Romero Gorski S. (Editora) Antropología social y cultural en Uruguay. (191-230) Montevideo: Facultad de Humanidades y Ciencias de la Educación, Editorial Nordan- Comunidad.

GUBER R. (2009) El salvaje metropolitano. Reconstrucción del conocimiento social en el trabajo de campo. Buenos Aires: Paidós

LEFEBVRE H. (2014) El espacio social. En La producción del espacio. (92-125) Madrid: Capitán Swing Libros,

ROCKWELL E. (1986) Reflexiones sobre el proceso etnográfico. En Para observar la escuela, caminos y nociones. La Práctica docente y sus contextos institucional y social. (Coord. E. Rockwell y J. Ezpeleta) (1-54) México, DIE.

RODRÍGUEZ C. (2015) Estado, clases y gentrificación. La política urbana como campo de disputa en tres barrios de la ciudad de Buenos Aires. En Perspectivas del estudio de la gentrificación en México y América Latina. (205- 228) México: UNAM, Instituto de Geografía.

SÁNCHEZ POMBO M. (2001) La evolución urbana de puerto norte. Desarrollo de un área industrial de la ciudad de rosario, argentina. Revista Bibliográfica de Geografía y Ciencias Sociales (Barcelona) № 290

SEGURA R. (2013) Los pliegues en la experiencia urbana de la segregación socio-espacial. Análisis comparativo de dos etnografías urbanas. En Carman M., Vieria da Cunha y Segura R. (Coordinadores) (143 - 169) Quito: FLACSO

SIGNORELLI A. (1999) Ciudad y conflicto. En Antropología urbana. (37-52) México: Anthropos Editorial.

\section{Ordenanzas:}

Municipalidad de Rosario, Ordenanza Básica 7892. Plan Especial $2^{\text {a }}$ Fase Centro de Renovación Urbana Raúl Scalabrini Ortiz Puerto Norte. Determinación. Sancionado 08/09/05 Promulgado 22/09/05

Municipalidad de Rosario, Ordenanza 8065, Ordenanza Complementaria. Plan de Detalle Unidad de Gestión $N^{\circ} 2$-Sector 1- del Plan Especial 2a ${ }^{\mathrm{a}}$ Fase Centro de Renovación Urbana Scalabrini Ortiz Puerto Norte. Aprobación. Sancionada: 02/11/16 Promulgada 21/11/16

Municipalidad de Rosario, ordenanza 8320, Plan de Detalle de la Unidad de Gestión No 1 . Plan Especial $2^{\mathrm{a}}$ Fase Centro de Renovación Urbana Scalabrini Ortiz- Puerto Norte. Definición. Sancionada: 16/10/08 Promulgada 04/11/08

\section{Fuentes electrónicas}

http://www.rosario.gov.ar/ArchivosWeb/pur 07.pdf Plan urbano Rosario 2007-2017 (Consulta: 24/02/18)

http://www.rosario.gov.ar/web/ciudad/planeamiento-urbano/plan-urbano-rosario/renovacion-puerto-norte (consulta: 24/02/18) 